\title{
INTRODUCTION \\ (In)famous neurological injuries and disease: cases and events of historical, political, cultural, and scientific impact: Part 2
}

\author{
James T. Goodrich, MD, PhD, ${ }^{1}$ Mark C. Preul, MD, ${ }^{2}$ and Chris A. Sloffer, MD, MBA ${ }^{3,4}$ \\ ${ }^{1}$ Division of Neurological Surgery, Albert Einstein College of Medicine, Montefiore Medical Center, Bronx, New York; ${ }^{2}$ Division \\ of Neurological Surgery, Barrow Neurological Institute, St. Joseph's Hospital and Medical Center, Phoenix, Arizona; ${ }^{3}$ Division of \\ Neurosurgery, Bronson Neuroscience Center; and ${ }^{4}$ Department of Surgery, Western Michigan University Homer Stryker School \\ of Medicine, Kalamazoo, Michigan
}

A s regular readers of Neurosurgical Focus are aware, we published the first issue dedicated to famous and infamous neurological injuries and cases of neurological disease in July 2015. We reviewed a remarkable number of high-quality historical articles and felt it necessary to dedicate the next issue of a historical nature to the same topic. Few topics exemplify the importance of the neurological system better than how injuries to and diseases of that system influence the course of history and the human condition (Figs. 1 and 2). More than the simple retelling of facts and myths, historians are interested in how a historical event was situated within the era in which it happened and how that event affected the society of its time and thereafter. We, and the authors of the individual articles, hope that we have succeeded in satisfying that goal with this issue.

In this issue, we present the articles in chronological order, beginning with Dowling and Goodrich's paper on 2 cases of head injury in Renaissance royal families that were treated by some of the greatest names in anatomy and surgery. We then move through the 19th century and into the 20th, highlighting injuries and diseases in the American Civil War and the Second World War that profoundly influenced the course of the wars and their resolutions. We present papers that consider the influence of neurological disease in the literature and its impact on the social and medical attitudes toward developmental abnormalities. We conclude with Lei and colleagues' discussion of the brain injury of Chinese mathematician Chen Jingrun. The wide range of subjects and the extent of the time period are indicative of the impact that neurological injuries have had on society throughout history.

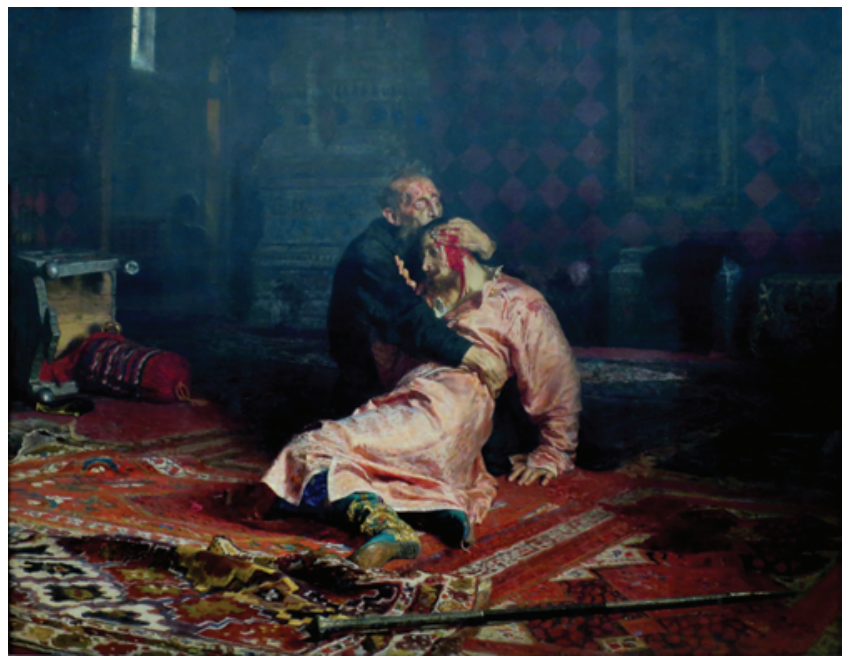

FIG. 1. The succession of the Russian tsars was affected by an ironic fatal head injury. In 1581 Ivan IV (Ivan the Terrible), given to episodic outbreaks of severe anger, beat his pregnant daughter-in-law (Yelena Sheremeteva) for wearing immodest clothing; the beating may have caused a miscarriage. Learning of his wife's miscarriage, Ivan Ivanovich confronted his father. Enraged during their argument, Ivan struck his son on the head with his pointed staff, fatally wounding him. This event is depicted in the famous and poignant 1885 painting by llya Repin (1844-1930), "Ivan the Terrible and his Son Ivan on November 16, 1581" (Tretyakov Gallery, Moscow). It is reported that Ivan was his father's favorite, and while being held by his weeping father, he forgave him his ensuing death. Ivan the Terrible died from a stroke while playing chess with Bogdan Belsky on March 28, 1584. Upon Ivan's death, the Russian throne was left to his unfit middle son Feodor, who died childless in 1598, ushering in the Russian Time of Troubles. Image is in the public domain (https://commons.wikimedia.org/wiki/File:REPIN_Ivan_ Terrible\%26lvan.jpg). 


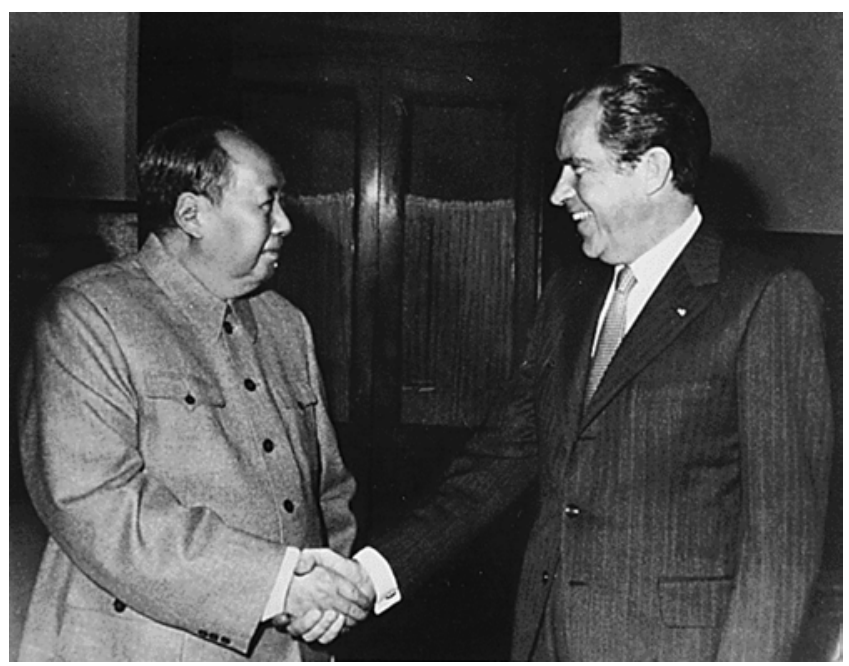

FIG. 2. President Nixon meets with China's Communist Party Leader, Mao Zedong (Tse-tung) on February 21, 1972. Mao was reportedly in a very weakened state when the American delegation arrived in Beijing. Mao had been a heavy smoker and had heart and lung conditions, and reports at this time indicate that he suffered from Parkinson's disease and amyotrophic lateral sclerosis. Mao was unable to participate much in governmental or administrative affairs; thus, without his direct leadership, perhaps the advancing effects of his neurological conditions caused the most tumultuous period of the Cultural Revolution to fortunately end. Image is in the public domain (https://catalog.archives. gov/id/194759).

We wish to extend our congratulations to the authors on their historical works. Many of these articles required careful review of primary and secondary sources from all over the world. We appreciate the effort necessary to do this research and sincerely hope that readers of the issue will enjoy their work.

http://thejns.org/doi/abs/10.3171/2016.4.FOCUS16182

\section{Disclosures}

Dr. Preul received support from the Newsome Family Chair in Neurosurgery Research for this work. 